\title{
Total contact cast wall load in patients with a plantar forefoot ulcer and diabetes
}

\author{
Lindy Begg ${ }^{1,2^{*}}$, Patrick McLaughlin ${ }^{3,4}$, Mauro Vicaretti ${ }^{1,2}$, John Fletcher ${ }^{1,2}$ and Joshua Burns ${ }^{1,5,6}$
}

\begin{abstract}
Background: The total contact cast (TCC) is an effective intervention to reduce plantar pressure in patients with diabetes and a plantar forefoot ulcer. The walls of the TCC have been indirectly shown to bear approximately $30 \%$ of the plantar load. A new direct method to measure inside the TCC walls with capacitance sensors has shown that the anterodistal and posterolateral-distal regions of the lower leg bear the highest load. The objective of this study was to directly measure these two regions in patients with Diabetes and a plantar forefoot ulcer to further understand the mechanism of pressure reduction in the TCC.

Methods: A TCC was applied to 17 patients with Diabetes and a plantar forefoot ulcer. TCC wall load (contact area, peak pressure and max force) at the anterodistal and posterolateral-distal regions of the lower leg were evaluated with two capacitance sensor strips measuring $90 \mathrm{~cm}^{2}$ (pliance ${ }^{\oplus}$, novel $\mathrm{GmbH}$, Germany). Plantar load (contact area, peak pressure and max force) was measured with a capacitance sensor insole (pedar ${ }^{\oplus}$, novel $\mathrm{GmbH}$, Germany) placed inside the TCC. Both pedar ${ }^{\circledast}$ and pliance ${ }^{\circledast}$ collected data simultaneously at a sampling rate of $50 \mathrm{~Hz}$ synchronised to heel strike. The magnitude of TCC wall load as a proportion of plantar load was calculated. The TCC walls were then removed to determine the differences in plantar loading between the TCC and the cut down shoe-cast for the whole foot, rearfoot, midfoot and forefoot (region of interest).

Results: TCC wall load was substantial. The anterodistal lower leg recorded $48 \%$ and the posterolateral-distal lower leg recorded $34 \%$ of plantar contact area. The anterodistal lower leg recorded $28 \%$ and the posterolateral-distal lower leg recorded $12 \%$ of plantar peak pressure. The anterodistal lower leg recorded $12 \%$ and the posterolateral-distal lower leg recorded $4 \%$ of plantar max force. There were significant differences in plantar load between the TCC and the cut down shoe-cast for the whole foot, rearfoot, midfoot and forefoot (region of ulcer). Contact area significantly increased by $5 \%$ beneath the whole foot, $8 \%$ at the midfoot and $6 \%$ at the forefoot in the shoe-cast $(p<0.05)$. Peak pressure significantly increased by $8 \%$ beneath the midfoot and $13 \%$ at the forefoot in the shoe-cast $(p<0.05)$. Max force significantly increased $6 \%$ beneath the midfoot in the (shoe-cast $p<0.05$ ).

Conclusion: In patients with diabetes and a plantar forefoot ulcer, the walls of the TCC bear considerable load. Reduced plantar contact area in the TCC compared to the shoe-cast suggests that the foot is suspended by the considerable load bearing capacity of the walls of the TCC which contributes mechanically to the pressure reduction and redistribution properties of the TCC.
\end{abstract}

Keywords: Diabetes, Foot ulcer, Wound, Total contact cast, Offloading, Plantar pressure

\footnotetext{
* Correspondence: Lindy.Begg@health.nsw.gov.au

${ }^{1}$ Foot Wound Clinic, Department of Surgery, Westmead Hospital, Sydney

2145 NSW, Australia

2Department of Surgery, Univeristy of Sydney, Westmead Hospital, Sydney,

Australia

Full list of author information is available at the end of the article
}

\section{Biomed Central}

C 2016 Begg et al. Open Access This article is distributed under the terms of the Creative Commons Attribution 4.0 International License (http://creativecommons.org/licenses/by/4.0/), which permits unrestricted use, distribution, and reproduction in any medium, provided you give appropriate credit to the original author(s) and the source, provide a link to the Creative Commons license, and indicate if changes were made. The Creative Commons Public Domain Dedication waiver (http://creativecommons.org/publicdomain/zero/1.0/) applies to the data made available in this article, unless otherwise stated. 


\section{Background}

Plantar neuropathic ulcers usually develop at sites of moderate to high repetitive cumulative load during normal walking [1-4]. It is recognised that plantar shear and shear-time integral magnitudes are also contributory factors [5]. Facilitation of healing occurs by reducing repetitive load to the ulcer [4]. Reducing plantar load at the site of an ulcer that is complicated by peripheral neuropathy continues to be a major challenge for clinicians and is critical to the outcome of care. If repetitive load persists, there is a chronic and ongoing disruption in the phases of healing producing cellular injury; which is recognised as one of the factors responsible for poor wound healing [4, 6-9]. It has been demonstrated histologically, that the application of a total contact cast results in the chronic ulcer resembling an acute wound in the reparative phase; that there is a reduction of inflammatory and reactive components, and an acceleration of reparative processes of the wound [10]. Since a neuropathic ulcer is a common precursor for amputation, an effective intervention should have a substantial impact on the prevention of amputation [11]. A fine balance must be achieved whereby plantar load is reduced to allow ulcer healing whilst allowing the patient to remain ambulatory. This is problematic since the thresholds for developing ulceration, likewise for healing a plantar ulcer, are yet to be established [3, 12-14].

The TCC is an effective intervention to reduce plantar pressure in patients with a neuropathic foot ulcer [15-18]. Offloading plantar neuropathic ulcers using a TCC is regarded as the 'gold standard' treatment for this condition [19-22] although the evidence supporting this has been referred to being of only moderate quality [17, 18, 23]. A TCC is generally regarded as a well-moulded, minimally padded cast that maintains contact with the entire plantar aspect of the foot and lower leg [1, 24-27] while providing protection of the wound from further injury [28, 29]. The TCC is traditionally non-removable and has been demonstrated to have superior wound healing outcomes compared to removable devices $[17,18,25,30]$. This has been attributed to the "forced compliance" aspect of the design of the TCC $[4,19,25,31]$.

Over time, the TCC has undergone several modifications; Sifoam at the plantar metatarsal area [13, 26, 32], creation of a window at the site of ulceration [33], $6 \mathrm{~mm}$ slowrebound cellular urethane and $6 \mathrm{~mm}$ soft cellular urethane along the plantar contour (cushion-modified TCC) $[34,35]$, application of a felt deflective pad at the ulcer site [4] and 'selective padding' has been used to protect the toes, bony prominences and anterior lower leg [28]. Additionally, fibreglass materials are frequently used instead of Plaster of Paris [36-38] while conventional canvas cast shoes have replaced the rubber heel $[39,40]$. The TCC has also been bi-valved to allow wound inspection and dressing, therefore rendering the cast removable $[41,42]$ however can be returned to a non-removable state with the use of a semi-rigid fibreglass bandage. Despite these modifications, the cast materials continue to be well moulded to the limb, with the materials closely approximating the contours of the limb ensuring the TCC is firm but not tight. Notwithstanding these modifications, the TCC acts by reducing localised pressure to the wound and immobilising the surrounding joints and soft tissue while preserving functional ambulation [1, 26, 29, 43]. Furthermore, the reduction of oedema $[21,29]$ and decreased intravascular fluid pressure improves microcirculation [44].

There are many factors contributing to the effectiveness of the TCC to offload pressure at the site of ulceration. Alteration of gait occurs with the TCC, such as a shorter stride length and velocity, thereby reducing the magnitude of pressure and cycles of repetition [26, 27, 43]. One major mechanism of action of the TCC has been attributed to "equalisation of plantar pressure". This refers to the reduction and redistribution of weight-bearing pressure across the entire plantar surface of the foot, including those areas that do not normally bear a large load and by increasing the plantar surface contact area [1, 21, 26, 27, 29]. However, previous work indicated that this was not always the case. Contact area data and regional pressure patterns comparing a cushion-modified TCC and a conventional TCC have shown pressure reduction and redistribution without increasing the plantar contact area [34]. These findings support a suggested mechanism of load transfer to the walls of the TCC $[1,21,26,46]$ or to the rearfoot [26].

The walls of the TCC have been indirectly shown to bear approximately $30 \%$ of the plantar load in small samples of healthy participants $[21,26,45]$. Direct measurement to measure load inside the TCC walls with capacitance sensors has shown that the TCC walls bear 23-34 \% of the plantar load [46]. Furthermore, the direct measurement method has shown that the anterodistal and posterolateral-distal regions of the lower leg bear the highest load, although this has only been evaluated in two participants without an ulcer. Therefore, the objective of this study was to directly measure these two regions in patients with Diabetes and a plantar forefoot ulcer to further understand the mechanism of pressure reduction in the TCC.

\section{Methods}

\section{Participants}

Participants were recruited from the Foot Wound Clinic, Westmead Hospital, New South Wales, Australia. All participants had diabetes mellitus and plantar forefoot ulceration, and had provided informed written consent in accordance with the Human Research Ethics Committee 
(HREC 2009/12/5.12 (3093). Demographic details, medical history, physical characteristics and ulcer diagnostics were collected (Table 1).

\section{Intervention}

An experienced podiatrist (LB) applied a cushion-modified TCC to each participant using a technique described previously [34]. Briefly, the technique involved a combination of rigid and semi-rigid cast materials, with the addition of a 6 $\mathrm{mm}$ slow-rebound cellular urethane and a $6 \mathrm{~mm}$ soft cellular urethane inlay (Fig. 1a). After 20 min, to allow for drying time as recommended by the manufacturer, each participant walked along a 9m walkway to familiarise themselves with walking whilst wearing the TCC. In order to accommodate the capacitance sensors, it was necessary to bivalve the TCC. Returning the bi-valved TCC to a TCC was done with particular care using non-stretch tape to firmly reaffix the edges and align the cast walls to ensure the TCC integrity during data collection. To all intent and purposes, the TCC was considered to be as robust as a newly applied TCC. A standard canvas TCC shoe (Blue Denim Cast shoe, Secure, Taiwan) with a slight rocker-sole was used with the TCC to assist with propulsion. On the contralateral foot, a canvas TCC shoe with a $12 \mathrm{~mm}$ cellular urethane inlay was worn to reduce any limb length difference between limbs. Following data collection, the walls of the TCC were removed to just below the malleolus to create a shoe-cast [21, 48] (Fig. 1b).

Table 1 Demographics and physical characteristics of the sample $(n=17)$

\begin{tabular}{|c|c|}
\hline Variable & Total participants \\
\hline Age (mean years, SD) & $57.2(12.9)$ \\
\hline Gender, Male, no. (\%) & $14(82.4 \%)$ \\
\hline Height (mean metres, SD) & $1.76(.06)$ \\
\hline Weight (mean kg, SD) & $102.5(28.1)$ \\
\hline BMI (mean kg/m², SD) & $33.6(8.3)$ \\
\hline Duration of Diabetes (mean years, SD) & $18.1(8.5)$ \\
\hline \multicolumn{2}{|l|}{ Ulcer location } \\
\hline Hallux, no. (\%) & $6(35)$ \\
\hline $1^{\text {st }} \mathrm{MPJ}$, no. $(\%)$ & $4(23)$ \\
\hline $2^{\text {nd }} M P J$, no. $(\%)$ & $1(16)$ \\
\hline $3^{\text {rd }}$ MPJ, no. (\%) & $2(12)$ \\
\hline $4^{\text {th }}$ MPJ, no. $(\%)$ & $2(12)$ \\
\hline $5^{\text {th }}$ MPJ, no. $(\%)$ & $2(12)$ \\
\hline Ulcer duration (mean weeks, SD) & $33.5(61.9)$ \\
\hline Toe pressure ${ }^{a}$ mean PPG, SD) & $104.1(43.1)$ \\
\hline Peripheral neuropathy ${ }^{\mathrm{b}}$ (frequency, \%) & $17(100 \%)$ \\
\hline
\end{tabular}

Note: ${ }^{a}$ Toe pressure was assessed using photoplethysmography (PPG, Hadeco Smartdop 30 EX Vascular Ultrasound Doppler, Japan)

${ }^{b}$ Peripheral neuropathy was assessed with a neurothesiometer and $10 \mathrm{~g}$ monofilament

\section{Outcome measures}

TCC wall load (contact area, peak pressure and max force) at two regions of the lower leg were evaluated with two capacitance sensor strips measuring $90 \mathrm{~cm}^{2}$ (pliance ${ }^{\circ}$, novel $\mathrm{GmbH}$, Germany). These regions were based upon the proof of concept study identifying the areas of highest TCC wall load [46] and are defined as anterodistal lower leg (along the tibia, running distally, specifically across the top of the ankle mortise over connective tissue structures) and posterolateral-distal lower leg (on the posterolateral part of the lower leg, running distally from a line slightly posterior to the fibula head and passing posterior to the lateral malleolus, specifically at the area of the lateral malleolus) (Fig. 2). The pliance ${ }^{\circ}$ sensor is $<1 \mathrm{~mm}$ thick and calibrated to a pressure range of $4.64-60 \mathrm{kPa}$.

Plantar load (contact area, peak pressure and max force) was measured with a capacitance sensor insole with a resolution of 1.2 sensors per $\mathrm{cm}^{2}$ (pedar, novel $\mathrm{GmbH}$, Germany) placed between the plantar surface of foot (in stockinet) and the cellular urethane material inside the TCC. Pedar $^{\circ}$ is an accurate, reliable, and valid system $[47,48]$.

\section{Experimental protocol and data analysis}

The participants walked at a comfortable self-selected walking speed along a $9 \mathrm{~m}$ walkway. Trials, whereby the participants walked at a velocity outside a $10 \%$ individual tolerance, were excluded from the study. Both pedar ${ }^{\circ}$ and pliance ${ }^{\circ}$ collected data simultaneously at a sampling rate of $50 \mathrm{~Hz}$ synchronised to the temporal event of heel strike. Each trial started with the participant standing with two feet together. Each participant was instructed to commence walking after the various data collection systems had commenced recording. In this way, the heel strike of the first step of each trial could be used for synchronisation purposes. This synchronisation was completed manually by combining video, plantar and TCC wall data. Each participant walked a minimum of two successful trials.

Descriptive statistics and normality of data distribution were computed in SPSS v22.0 (IBM SPSS Statistics for Windows, Armonk, NY, USA). The magnitude of TCC wall load as a proportion of plantar load was calculated. Following removal of the cast walls, the difference in plantar loading between the TCC and the shoe-cast for the whole foot and three clinically relevant regions of the foot, including rearfoot, midfoot and forefoot (region of interest as the site of ulceration), were calculated using the Novel software (novel GmbH, Germany) [49]. Paired sample ttests were undertaken to assess significance between TCC and shoe-cast conditions. The alpha value was set at 0.05 .

\section{Results}

Seventeen patients with diabetes and a forefoot ulcer volunteered to participate in this study. Walking speed 

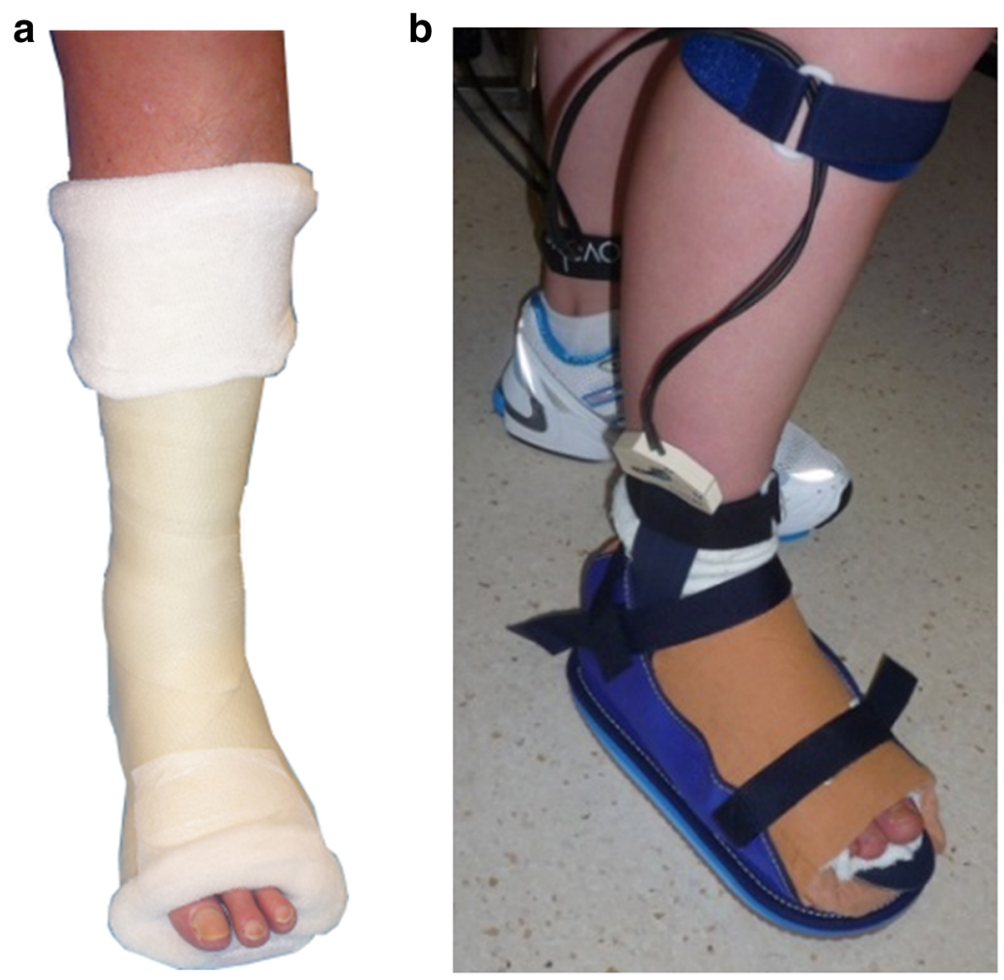

Fig. 1 The TCC (a) and shoe-cast (b) conditions

was comparable between conditions (TCC $0.77+/-0.21$ $\mathrm{m} / \mathrm{s}$, shoe-cast $0.79+/-0.23 \mathrm{~m} / \mathrm{s})(p>0.05)$.

Contact area, max force and peak pressure inside the walls of the TCC at the anterodistal and posterolateral distal regions of the lower leg are shown in Table 2.

The anterodistal lower leg recorded $48 \%$ and the posterolateral distal lower leg recorded $34 \%$ of the mean plantar contact area of the whole foot in the TCC.

The anterodistal lower leg recorded $28 \%$ and the posterolateral distal lower leg recorded $12 \%$ of the mean plantar peak pressure of the whole foot in the TCC.

The anterodistal lower leg recorded $12 \%$ and the posterolateral distal lower leg recorded $4 \%$ of the mean plantar max force of the whole foot in the TCC.

Differences in contact area, max force and peak pressure between the total contact cast and the shoe-cast for the whole foot, rearfoot, midfoot and forefoot (region of ulcer) are shown in Table 3. When the TCC was cut down to a shoe-cast, contact area significantly increased by $7.1 \mathrm{~cm}^{2}$ (5\%) beneath the whole foot, $4.3 \mathrm{~cm}^{2}(8 \%)$ at the midfoot and $4.7 \mathrm{~cm}^{2}(6 \%)$ at the forefoot $(p<0.05)$. Peak pressure significantly increased by $8.9 \mathrm{kPa}(8 \%)$ beneath the midfoot and by $17.5 \mathrm{kPa}(13 \%)$ at the forefoot $(p<0.05)$. Max force significantly increased by 13.2 $\mathrm{N}(6 \%)$ beneath the midfoot $(p<0.05)$.

\section{Discussion}

\section{Main findings}

In patients with diabetes and a forefoot plantar ulcer, the walls of the TCC recorded considerable load (contact area, peak pressure and max force). It is of interest that the region of greatest load (anterodistal lower leg), did not occur at the rigid cast walls but at a region whereby the limb was encased with Soft Cast $^{\mathrm{Tm}}$ which is a semi-rigid cast material. This finding supports the literature that diligent moulding of the cast material around body contours can increase the level of stiffness and strength of the cast material to carry substantial load [52].

There were significant differences in plantar load (contact area, peak pressure and max force) between the TCC and the cut down shoe-cast for the whole foot, rearfoot, midfoot and forefoot (region of ulcer). An interesting finding was that there was a significant decrease of the plantar contact area in the TCC compared to the shoe-cast, with concomitant lowering of plantar peak pressure beneath the midfoot and forefoot in the TCC. These results contradict some aspects of the "equalisation of plantar pressure" theory [1, 21, 26, 29]. Instead, the reduced plantar contact area in the TCC, compared to the shoecast, suggests that the foot is suspended by the considerable load bearing capacity of the walls of the TCC, which contributes mechanically to the pressure reduction and 

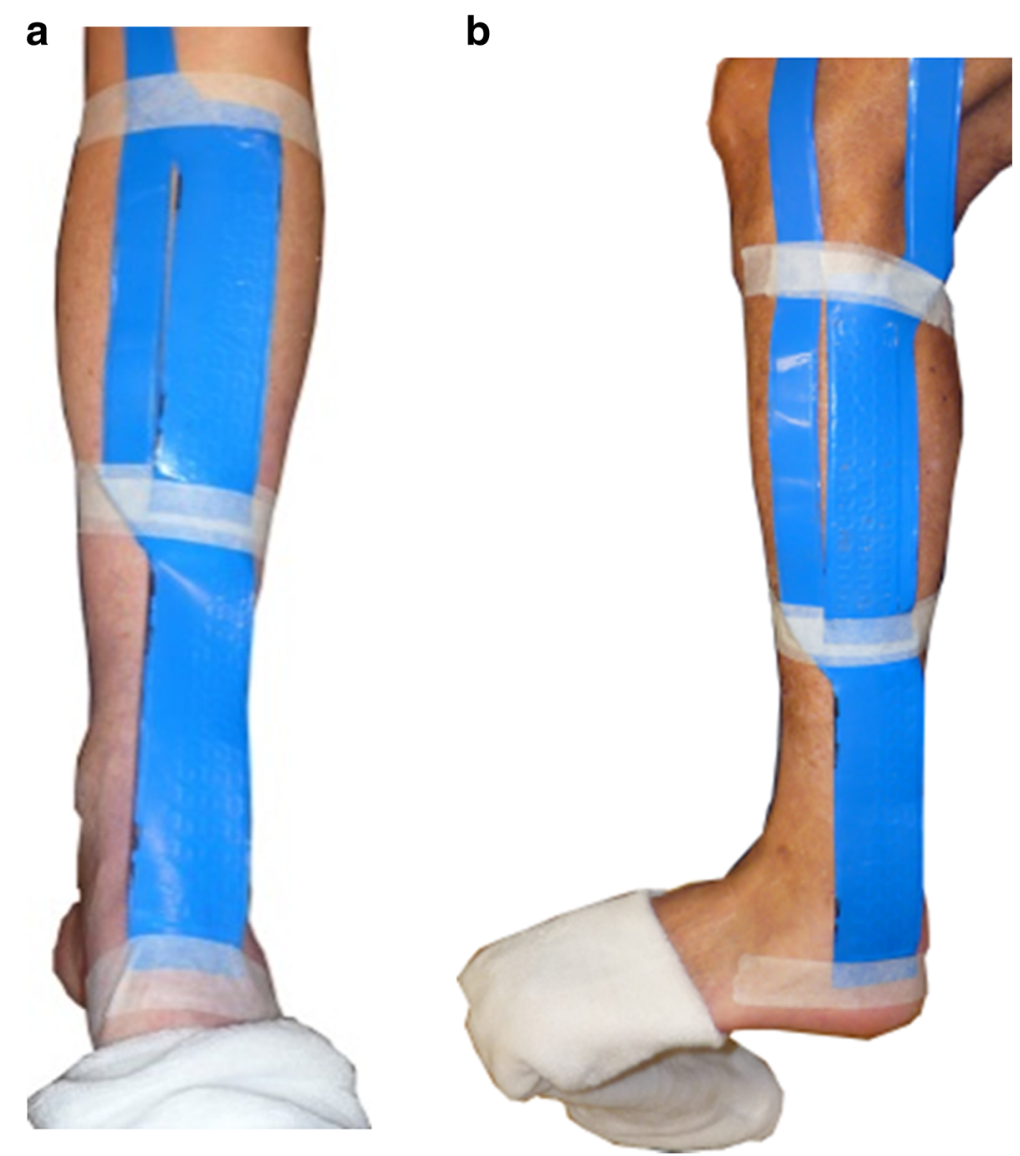

Fig. 2 Capacitance sensor strips (pliance ${ }^{\oplus}$, novel GmbH, Germany) placed at the anterodistal (a) and posterolateral-distal (b) regions of the lower leg

redistribution properties of the TCC. Our data support the load transference theory of the TCC $[21,26,45]$ which we can now measure directly with capacitance sensors.

\section{Comparison with the literature}

Various studies have assessed load transference to the cast walls by indirect methods in small samples of healthy participants. Shaw and colleagues [26], simultaneously collected pedar ${ }^{\ominus}$ data beneath the foot of five participants with elevated forefoot pressures wearing a TCC (modified with forefoot sifoam), whilst walking across a force platform. It was reported that the difference in impulse, with the plantar insole reporting smaller values than the force platform, was indicative of load transfer to the cast wall.

Table 2 Descriptive novel pliance ${ }^{\circledast}$ data for the walls of the TCC $(n=17)$

\begin{tabular}{llll}
\hline Region of interest & $\begin{array}{l}\text { Contact } \\
\text { area }\left[\mathrm{cm}^{2}\right]\end{array}$ & Peak pressure $[\mathrm{kPa}]$ & Max force $[\mathrm{N}]$ \\
\hline Antero-distal lower leg & $71.0(12.2)$ & $44.1(15.2)$ & $74.9(35.2)$ \\
$\begin{array}{l}\text { Postero-lateral distal } \\
\text { lower leg }\end{array}$ & $51.2(13.3)$ & $18.4(15.2)$ & $24.7(26.5)$ \\
\hline
\end{tabular}

Note: Data are mean (SD)
Table 3 Plantar pressure data for the total contact cast compared to the shoe-cast $(n=17)$

\begin{tabular}{|c|c|c|c|}
\hline $\begin{array}{l}\text { Region of } \\
\text { interest }\end{array}$ & Contact area $\left[\mathrm{cm}^{2}\right]$ & Peak pressure [kPa] & Max force $[\mathrm{N}]$ \\
\hline \multicolumn{4}{|c|}{ Total Contact Cast } \\
\hline - Whole foot & $149.6(18.1)$ & $158.8(52.6)$ & $592.4(201.1)$ \\
\hline - Rearfoot & $19.7(5.5)$ & $128.5(45.0)$ & $130.0(59.4)$ \\
\hline - Midfoot & $54.5(6.2)$ & $112.9(42.3)$ & $213.5(85.6)$ \\
\hline - Forefoot & $75.5(12.1)$ & $131.4(59.5)$ & $247.8(122.2)$ \\
\hline \multicolumn{4}{|l|}{ Shoe-cast } \\
\hline - Whole foot & $156.7(11.9)^{*}$ & $171.1(57.5)$ & $602.1(176.9)$ \\
\hline - Rearfoot & $19.7(5.6)$ & $131.6(43.1)$ & $106.7(66.2)$ \\
\hline - Midfoot & $56.8(4.7)^{*}$ & $121.8(37.2)^{*}$ & $226.7(83.3)^{*}$ \\
\hline - Forefoot & $80.2(8.8)^{*}$ & $148.9(64.5)^{*}$ & 268.7 (116.5) \\
\hline
\end{tabular}

Note: Data are mean (SD)

*Significant difference compared to the total contact cast $(p<0.05$; paired samples t-test) 
This difference was calculated as $31.2 \%$ of the impulse measured by the force plate. Leibner and co-workers collected pedar ${ }^{\circ}$ data beneath the foot in 12 healthy participants wearing a TCC during walking. The TCC was then cut-down to produce a shoe-cast and data collection was repeated [21]. The smaller values for average force per step in the TCC condition were attributed to a transfer of load to the cast walls compared to the shoecast condition. This transfer of load was calculated to be $36 \%$ of the average force per step measured in the shoe-cast condition. Finally, Tanaka and colleaugues [45], assessed five healthy participants and measured plantar pressure (F-SCAN, Tekscan Inc, South Boston, Massachusetts) in a conventional Patella Tendon Bearing Cast (PTB) with a heel (used for the treatment of below knee fractures), and the contralateral side (extension shoe) and attributed a $30 \%$ offloading to the cast walls. Direct measurement of inside the TCC walls with the use of capacitance sensors has shown that the TCC walls bear 23$34 \%$ of the plantar load [46]. It is diffcult to compare these studies because they all report different units of measurement, cast technique, terminal devices (cast shoes and heels), TCC rigidity and cushioning materials. Neverthless, the reduction of plantar load via transfer to cast walls seems to be in the vicinity of $30 \%$.

\section{Clinical implications}

The mechanism of action, that suspension of the foot by the considerable load bearing capacity of the TCC walls contributes to the pressure reduction and redistribution properties of the TCC, is supported by the literature [21, $26,34,45]$. It is known that sufficient tissue is required at the plantar metatarsal area to allow soft tissue compression under load bearing for pressure distribution [51] and that there is a strong inverse relationship between plantar tissue thickness and plantar pressure magnitude in patients with diabetes and neuropathy [52]. In this study, the TCC was cushion-modified by incorporating a full-length $6 \mathrm{~mm}$ slow-rebound cellular urethane and $6 \mathrm{~mm}$ soft cellular urethane inlay, as result of previous data demonstrating superior offloading compared to a conventional TCC [34]. It is postulated that the $12 \mathrm{~mm}$ cellular urethane acts to enhance the plantar fat pad thickness, improve the shock absorption capabilities and to act as a buffer to create a cavity between the plantar surface of the foot and the rigid and semi-rigid cast material. This concept is supported by Tanaka et al. who found that the addition of a $10 \mathrm{~mm}$ soft sponge in a conventional Patella Tendon Bearing Cast (PTB) cast increased offloading from $30 \%$ to $56 \%$ by producing a space between the foot and the cast. Furthermore, when a $30 \mathrm{~mm}$ space was created via an air bellows bag, there was a $100 \%$ offloading. Tanaka et al. suggested that this space results in suspension of the leg by the inner region of the cast [45]. Shaw et al. refer to the contribution of the soft foam beneath the forefoot as creating a cavity and removing the load bearing surface from the metatarsal heads to suspend the foot [26].

Based on this study and previous studies in the literature, the offloading mechanism of the TCC can be attributed to a combination of the following factors:

- Suspension of the foot by the considerable load bearing capacity of the TCC walls, especially the anterodistal and the posterolateral-distal regions of the lower leg.

- Reduction of plantar pressure by incorporating a full-length $6 \mathrm{~mm}$ slow-rebound cellular urethane and $6 \mathrm{~mm}$ soft cellular urethane inlay inside the TCC.

- Redistribution of plantar pressure by a well-moulded TCC using a combination of rigid and semi-rigid cast materials, extending proximal to the ankle.

- Fixation of the ankle at $90^{\circ}$ within the TCC, thereby eliminating plantarflexion and dorsiflexion. The addition of a cast shoe with a rockersole assists with propulsion.

- Forced compliance and alteration of gait, such as shorter stride length and velocity.

Therefore in addition to biomechanical factors in reducing plantar forefoot load, wearing a TCC alters the patient behaviour in terms of "forced" compliance and acting to reduce activity levels [25]. There is a reduction of the number of steps per day and therefore a concomitant reduction of cumulative plantar load and stress [53]. Thus the combination of biomechanical factors and alteration of behaviour contributes to the successful wound healing attributes of the TCC.

The results of this study also suggests that when prefabricated devices are selected to offload forefoot plantar ulceration, that the design of such device should mimic a TCC and incorporate rigid "walls" extending proximally, medially and laterally at the lower leg, with the lower limb fixed securely to minimise shear forces and should contain a cushioning insole and be fixated at the ankle at $90^{\circ}$ with a rockersole.

Additionally, whenever possible prefabricated devices should be made non-removable using a semi-rigid cast bandage or cohesive bandage. Furthermore, that the device should be lightweight and be of low profile to encourage adherence and minimise apparent leg length discrepancy. If oedema exists, compression should be applied. It is recommended that the patient be advised to take shorter, slower steps and restrict activity levels. All these factors will contribute to enhance ulcer healing.

\section{Limitations}

Due to technical limitations, only perpendicular forces were measured and the cast wall load area of measurement 
was limited to $90 \mathrm{~cm}^{2}$. Notwithstanding, in regard to the cast wall data, this is the first study to measure such load directly in a patient population. A further limitation of this study is that it was cross-sectional and that TCC wall load characteristics over time were not assessed. The majority of participants in this study were representative of patients presenting with plantar forefoot ulceration to our tertiary hospital. As such, while the results may have differed in people with lower BMI, the findings would not have been generalisable to the relevant clinical population.

\section{Conclusion}

Offloading plantar neuropathic ulcers using a TCC is regarded as the 'gold standard' in patients with diabetes. This study shows that the walls of the TCC bear considerable load when measured directly in patients with diabetes and forefoot ulceration. Reduced plantar contact area in the TCC, compared to the shoe-cast, suggests that the foot is suspended by the considerable load bearing capacity of the walls of the TCC, which supports the load transference theory and contributes mechanically to the pressure reduction and redistribution properties of the TCC. Limb suspension seems to be an important component of effective TCC offloading, particularly when used in conjunction with cushioning materials. Any off-theshelf offloading device should mimic these essential design features of the TCC.

\section{Competing interests}

PM is the Australian and New Zealand agent for novel GmbH, Germany. JB receives funds from the NHMRC (National Health and Medical Research Council of Australia, Fellowship \#1007569 and Centre of Reseach Excellence \#1031893), NIH (National Institutes of Neurological Disorders and Stroke and Office of Rare Diseases, \#U54NS065712), Australian Podiatry Education and Research Foundation, Podiatry Council of New South Wales, Charcot Marie Tooth Association, Muscular Dystrophy Association, CMT Association of Australia.

\section{Authors' contributions}

$L B, P M, J B$ participated in the design of the study and secured funding. LB applied the total contact casts. LB and PM performed data collection. LB, PM and JB conducted data analysis. All authors reviewed and approved the final manuscript.

\section{Acknowledgement}

This study was funded by the Australian Podiatry Education \& Research Fund (APERF). Pliance ${ }^{\circledast}$ sensors were provided by novel $\mathrm{GmbH}$, Germany.

\footnotetext{
Author details

${ }^{1}$ Foot Wound Clinic, Department of Surgery, Westmead Hospital, Sydney 2145 NSW, Australia. ${ }^{2}$ Department of Surgery, Univeristy of Sydney, Westmead Hospital, Sydney, Australia. ${ }^{3}$ Centre for Chronic Disease Prevention, College of Health and Biomedicine, Victoria University, Melbourne, Australia. ${ }^{4}$ Institute of Sport, Exercise and Active Living, Victoria University, Melbourne, Victoria, Australia. ${ }^{5}$ Arthritis and Musculoskeletal Research Group, Faculty of Health Sciences, The University of Sydney, Sydney, New South Wales, Australia. ${ }^{6}$ Paediatric Gait Analysis Service of New South Wales, Sydney Children's Hospitals Network (Randwick and Westmead), Sydney, New South Wales, Australia.
}

Received: 30 July 2015 Accepted: 30 October 2015

Published online: 07 January 2016

\section{References}

1. Novick A, Birke JA, Graham SL, Koziatek E. Effect of a Walking Splint and Total Contact Casts on Plantar Forces. J Prosthet Orthot. 1991;3(4):168-78.

2. Veves A, Murray HJ, Yoing MJ, Boulton AJM. The risk of foot ulceration in diabetic patients with high foot pressure: a prospective study. Diabetologia. 1992:35(7):660-3.

3. Lavery LA, Armstrong DG, Wunderlich RP, Tredwell J, Boulton AJ. Predictive value of foot pressure assessment as part of a population-based diabetes disease management program. Diabetes Care. 2003;26(4):1069-73.

4. Bell D. Evidence-based rationale for offloading treatment modalities. Surg Technol Int. 2008;17:113-7.

5. Yavuz M. American Society of Biomechanics Clinical Biomechanics Award 2012: Plantar shear stress distributions in diabetic patients with and without neuropathy. Clin Biomech. 2014;29(2):223-9.

6. Jeffcoate WJ, Lipsky BA, Berendt AR, Cavanagh PR, Bus SA, Peters EJ, et al. Unresolved issues in the management of ulcers of the foot in diabetes. Diabet Med. 2008;25(12):1380-9.

7. Alexiadou K, Doupis J. Management of Diabetic Foot Ulcers. Diabet Therapy. 2012;3(1):1-15

8. Apelqvist J. Practical guidelines in the management and prevention of the diabetic foot. Diabet Metab Res Rev. 2008:24(Supp1):S181-7.

9. Ali R, Qureshi A, Yaqooob MY, Shakil M. Total contact cast for neuropathic diabetic foot ulcers. J Coll Physicians Surg Pak. 2008;18(11):695-8.

10. Piaggesi A, Viacava P, Rizzo L, Naccarato G, Baccetti F, Romanelli M, et al. Semiquantitative analysis of the histopathological features of the neuropathic foot ulcer: effects of pressure relief. Diabetes Care. 2003;26(11):3123-8.

11. Armstrong DG, Lavery LA. Evidence-based options for off-loading diabetic wounds. Clin Podiatr Med Surg. 1998;15(1):95-104.

12. Waldecker U. Pedographic classification and ulcer detection in the diabetic foot. Foot Ankle Surg. 2012;18(1):42-9.

13. Petre M, Tokar P, Kostar D, Cavanagh PR. Revisiting the total contact cast: maximizing off-loading by wound isolation. Diabetes Care. 2005;28(4):929-30

14. Armstrong DG, Peters EJ, Athanasiou KA, Lavery LA. Is there a critical level of plantar foot pressure to identify patients at risk for neuropathic foot ulceration? J Foot Ankle Surg. 1998;37(4):303-7.

15. Shah S. Clinical and Economic Benefits of Healing Diabetic Foot Ulcers With a Rigid Total Contact Cast. Wounds. 2012;24(6):152-9.

16. McGuire J, Greene T. What Is the "Essential" TCC?... Total Contact Cast. Podiatry Manage. 2014;33(6):117-25

17. Morona JK, Buckley ES, Jones S, Reddin EA, Merlin TL. Comparison of the clinical effectiveness of different off loading devices for the treatment of neuropathic foot ulcers in patients with diabetes: a systematic review and meta analysis. Diabetes Metab Res Rev. 2013;29(3):183-93.

18. Lewis J, Lipp A. Pressure relieving interventions for treating diabetic foot ulcers. The Cochrane Database of Systemic Reviews 2013, Issue 1. Art. No.: CD002302. doi:10.1002/14651858.CD002302.pub2.

19. Boulton AJ. Pressure and the diabetic foot: clinical science and offloading techniques. Am J Surg. 2004;187(5A):17S-24S.

20. Wu SC, Armstrong DG. [Commentary on] Semiquantitative analysis of the histopathological features of the neuropathic foot ulcer: effects of pressure relief. Foot Ankle Q-Sem J. 2005;17(3):89.

21. Leibner ED, Brodsky JW, Pollo FE, Baum BS, Edmonds BW. Unloading mechanism in the total contact cast. Foot Ankle Int. 2006;27(4):281-5.

22. Faglia E, Faglia E, Caravaggi C, Clerici G, Sganzaroli A, Curci V, et al. Effectiveness of removable walker cast versus nonremovable fiberglass off-bearing cast in the healing of diabetic plantar foot ulcer: a randomized controlled trial. Diabetes Care. 2010;33(7):1419-23.

23. Snyder RJ, Frykberg RG, Rogers LC, Applewhite AJ, Bell D, Bohn G, et al. The Management of Diabetic Foot Ulcers Through Optimal Off-Loading. J Am Podiatr Med Assoc. 2014;104(6):555-67.

24. Birke JA, Pavich MA, Patout Jr CA, Horswell R. Comparison of forefoot ulcer healing using alternative off-loading methods in patients with diabetes mellitus. Adv Skin Wound Care. 2002;15(5):210.

25. Armstrong DG, Nguyen $\mathrm{HC}$, Lavery LA, van Schie $\mathrm{CH}$, Boulton AJ, Harkless LB. Off-loading the diabetic foot wound: a randomized clinical trial. Diabetes Care. 2001;24(6):1019-22.

26. Shaw JE, Hsi WL, Ulbrecht JS, Norkitis A, Becker MB, Cavanagh PR. The mechanism of plantar unloading in total contact casts: implications for design and clinical use. Foot Ankle Int. 1997;18(12):809-17. 
27. Lavery LA, Vela LA, Lavery DC, Quebedeaux TL. Total contact casts: pressure reduction at ulcer sites and the effect on the contralateral foot. Arch Phys Med Rehabil. 1997;78(11):1268-71

28. Birke JA, Patout Jr CA. The contact cast: an update and case study report (see medscape/email from libary-couldnt save). Wounds. 2000;12(2):26-31.

29. Conti SF, Martin RL, Chaytor ER, Hughes C, Luttrell L. Plantar Pressure Measurements During Ambulation in Weightbearing Conventional Short Leg Casts and Total Contact Casts. Foot Ankle Int. 1996;17(8):464-9.

30. Mueller MJ, Diamond JE, Sinacore DR, Delitto A, Blaire 3rd VP, Drury DA, et al. Total contact casting in treatment of diabetic plantar ulcers. Controlled clinical trial. Diabetes Care. 1989;12(6):384-8.

31. Gutekunst DJ, Hastings MK, Bohnert KL, Stube MJ, Sinacore DR. Removable cast walker boots yield greater forefoot off-loading than total contact casts. Clin Biomech. 2011;26(6):649-54.

32. Hartsell HD, Fellner C, Frantz R, Saltzman CL. The Repeatability of Total Contact Cast Applications: Implications for Clinical Trials. J Prosthet Orthot. 2001;13(1):4-7.

33. Caravaggi C, De Giglio R, Pritelli C, Sommaria M, Dalla Noce S, Faglia E, et al. HYAFF 11-Based Autologous Dermal and Epidermal Grafts in the Treatment of Noninfected Diabetic Plantar and Dorsal Foot Ulcers: A prospective, multicenter, controlled, randomized clinical trial. Diabetes Care. 2003;26(10):2853-9.

34. Burns J, Begg L. Optimizing the offloading properties of the total contact cast for plantar foot ulceration. Diabet Med. 2011;28(2):179-85.

35. Pirozzi K, McGuire J, Meyr AJ. A comparison of two total contact cast constructs with variable body mass. J Wound Care. 2014;53(5):588-97.

36. Frantz RA, Hartsell HD, Brand RA, Saltzman CL. The effects of total contact casting materials on plantar pressures. Foot Ankle Int. 2004;25(2):73-8.

37. Beuker BJ, Van Deursen RW, Price P, Manning EA, Van Baal JG, Harding KG. Plantar pressure in off-loading devices used in diabetic ulcer treatment. Wound Repair Regen. 2005;13(6):537-42.

38. Ermolaeva O, Galslyan G, Bublik E, Pryakhina N, Maximova N, Udovichenko O. Efficacy of a reusable total-contact cast. Diabetic Foot. 2010;13(1):18.

39. Dhalla R, Johnson JE, Engsber J. Can the use of a terminal device augment plantar pressure reduction with a total contact cast? Foot Ankle Int. 2003;24(6):500-5.

40. Lavery LA, Fleishli JG, Laughlin TJ, Vela SA, Lavery DC, Armstrong DG. Is postural instability exacerbated by off-loading devices in high risk diabetics with foot ulcers? Ostomy Wound Manage. 1998:44(1):26.

41. Boninger ML, Leonard Jr JA. Use of bivalved ankle-foot orthosis in neuropathic foot and ankle lesions. J Rehabil Res Dev. 1996;33(1):16.

42. Caputo GM, Ulbrecht JS, Cavanagh PR. The total contact cast: a method for treating neuropathic diabetic ulcers. Am Fam Physician. 1997:55(2):605-11.

43. Hartsell HD, Brand RA, Saltzman CL. Total contact casting: its effect on contralateral plantar foot pressure. Foot Ankle Int. 2002;23(4):330-4.

44. Baumhauer JF, Wervey R, McWilliams J, Harris GF, Shereff MJ. A comparison study of plantar foot pressure in a standardized shoe, total contact cast, and prefabricated pneumatic walking brace. Foot Ankle Int. 1997;18(1):26-33.

45. Tanaka H, Nagata K, Goto T, Hoshiko H, Inoue A. The effect of the patella tendon-bearing cast on loading. J Bone Joint Surg Br. 2000;82-B:228-32.

46. Begg L, McLaughlin P, Manning L, Vicaretti M, Fletcher J, Burns J. A novel approach to mapping load transfer from the plantar surface of the foot to the walls of the total contact cast: a proof of concept study. J Foot Ankle Res. 2012;5(1):32

47. Boyd LA, Bontrager EL, Mulroy SJ, Perry J. The reliability and validity of the Novel Pedar system of in-shoe pressure measurement during free ambulation. Gait Posture. 1997;5(2):165.

48. Murphy DF, Beynnon BD, Michelson JD, Vacek PM. Efficacy of plantar loading parameters during gait in terms of reliability, variability, effect of gender and relationship between contact area and plantar pressure. Foot Ankle Int. 2005:26(2):171-9.

49. Burns J, Crosbie J, Hunt A, Ouvrier R. The effect of pes cavus on foot pain and plantar pressure. Clin Biomech. 2005:20(9):877-82

50. White RSJ, Wardlaw D, Diamandopoulos Z, Anderson R. Biomechanical assessment of gait in below knee walking casts. Prosthet Orthot Int. 1999;23(23):142-51.

51. Cavanagh PR. Plantar soft tissue thickness during ground contact in walking. J Biomech. 1999:32(6):623-8.

52. Abouaesha F, van Schie CH, Armstrong DG, Boulton AJ. Plantar soft-tissue thickness predicts high peak plantar pressure in the diabetic foot. J Am Podiatr Med Assoc. 2004;94(1):39-42.

53. Lott DJ, Zou D, Mueller MJ. Pressure gradient and subsurface shear stress on the neuropathic forefoot. Clin Biomech. 2008;23(3):342-8.

\section{Submit your next manuscript to BioMed Central and take full advantage of:}

- Convenient online submission

- Thorough peer review

- No space constraints or color figure charges

- Immediate publication on acceptance

- Inclusion in PubMed, CAS, Scopus and Google Scholar

- Research which is freely available for redistribution

Submit your manuscript at www.biomedcentral.com/submit 